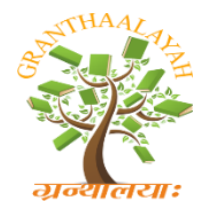

\author{
INTERNATIONAL JOURNAL OF RESEARCH - \\ GRANTHAALAYAH \\ A knowledge Repository
}

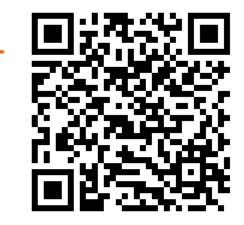

Science

\title{
CONTENT OF SUGARS IN FRESH GRAPES AND RAISINS, AND FRESH AND DRIED APRICOT: A COMPARATIVE STUDY
}

\author{
Maha Abdalla Alnuwaiser *1 \\ ${ }^{* 1}$ Department of Chemistry, Faculty of Science, Princess Nora bint Abdul Rahman University, \\ P.O. Box 28445, Riyadh, 11437, Saudi Arabia
}

\begin{abstract}
Sugars, mainly fructose, glucose, maltose and sucrose ratios in the fresh red grape and raisins and in the fresh and dried apricot fruit were determined by High Performance Liquid Chromatography, HPLC, equipped with Ec 250/4.6 Nucleodur 100-5 NH2-RP column and Refractometer -RID as a detector. Each type of the four samples was separately homogenized after removing the seeds from the samples before crushing, and in this study the deionized water was used for extraction of sugars.

The ratio of each sugar in the four investigated cultivars was compared as well as comparing the contents of total sugars between these types, and it became obvious that fructose and glucose recorded significant increase rather than sucrose and maltose in these cultivars.

Comparison has also been conducted for determination of fructose, glucose, maltose and sucrose ratios between the fresh red grapes and raisins on one hand, and between the fresh apricot fruit and dried apricot on the other. The study showed that the raisins contain high level of fructose, glucose, maltose and sucrose compared to the fresh grapes. Moreover, the sugar content in the dried apricot was higher than the sugar contents in the fresh apricot fruit.
\end{abstract}

Keywords: Fresh Grapes; Raisins; Apricot; HPLC.

Cite This Article: Maha Abdalla Alnuwaiser. (2017). "CONTENT OF SUGARS IN FRESH GRAPES AND RAISINS, AND FRESH AND DRIED APRICOT: A COMPARATIVE STUDY." International Journal of Research - Granthaalayah, 5(11), 177-186. https://doi.org/10.29121/granthaalayah.v5.i11.2017.2345.

\section{Introduction}

The major components in grape are water followed by sugars mainly fructose, glucose and sucrose. Grape is an excellent source of many nutrients able to contribute to a healthy diet. The sugar content of the juice of ripe grapes varies between 150 to $250 \mathrm{~g} / \mathrm{L}$. In unripe berries, glucose is the predominant sugar. At the ripening stage, glucose and fructose are usually present in equal amounts (1:1 ratio). In overripe grapes, the concentration of fructose exceeds that of glucose. In ripe grapes, there is some variation in the glucose to fructose ratio among the grape varieties. Fructose is a natural sugar found in many foods like fruits and honey. When fructose is attached 
to a sugar called glucose, it forms sucrose or "table sugar". Fructose is very sweet and is often made into high fructose corn syrup, used in soft drinks and processed foods. Fructose is absorbed in the small intestine in a couple of ways. If glucose is present in equal amounts with fructose, the body absorbs fructose better. Free fructose without matching glucose is absorbed more slowly, and this may cause digestive symptoms for some [1].

There are several methods reported in the literature for determining components in grape fruit and their derivative. A. Fateh et al., 2007 were used HPLC and AAS to determine sugars and mineral salts in Tunisian fresh figs [2]. The HPLC separation of standard monosaccharide and disaccharides were successfully achieved by M. Takako et al., 2001 using new prepared stationary phase [3]. Glucose and fructose were analyzed in wine using HPLC with modified polar- boned NH Silica phase column and RID performed by M. Enzo et al., 2007 [4].

The word "raisin" dates back to Middle English and is a loanword from Old French; in modern French, raisin means "grape", while a dried grape is a raisin sec, or "dry grape". The old French word, in turn, developed from the Latin word racemus, "a bunch of grapes" [5]. Raisin varieties depend on the type of grape used, and are made in a variety of sizes and colors including green, black, brown, blue, purple, and yellow. Raisins are produced in many regions of the world and may be eaten raw or used in cooking, baking, and brewing. In the United Kingdom, Ireland, New Zealand, and Australia, the word "raisin" is reserved for the dark-colored dried large grape [6], with "sultana" being a golden- colored dried grape, and "currant" being a dried small Black Corinth seedless grape [7].

Raisins are a rich source of carbohydrate. Glucose and fructose are the main sugars detected in white and red grapes cultivars. As reported by other authors for grapes and plums, a reduction of sugar content was observed during drying, probably caused by non-enzymatic browning reactions. Raisins can contain up to $72 \%$ sugars by weight, most of which is fructose and glucose. They also contain about 3\% protein and 3.7\%-6.8\% dietary fiber Raisins, like prunes and apricots, are also high in certain antioxidants, but have lower vitamin $\mathrm{C}$ content than fresh grapes. Raisins are low in sodium and contain no cholesterol [6].

Data presented at the American College of Cardiology's $61^{\text {st }}$ Annual Scientific Session in 2012 suggest that, among individuals with mild increases in blood pressure, the routine consumption of raisins (three times a day) may significantly lower blood pressure, especially when compared to eating other common snacks. Traditionally raisins are obtained by sun drying of the fruit for eight to ten days, which substantially reduces water content. This drying method is cheap, but there is a risk of damage due to dust and insect infection [8] and the sensory quality can also be seriously damaged during exposure to sunlight [9]. Convective drying is one of the oldest and alternative dehydration methods in which hot air removes the water from the fruit surface. This creates a diffusion gradient in the food that moves the water from the interior to the outer surface [10]. However, this process decreases the quality of the final product [11]. Moreover, dehydration causes damages in texture, color, taste and nutritional value of food due to the high temperatures and long drying times required in the process [12].

The content of reducing sugar recorded a higher value in raisins made from Thompson seedless. A significant increase in most of the biochemical constituents, such as proteins and reducing 
sugar was recorded in raisins rather than in fresh grapes [13]. Apricot (Prunusarmeniaca L.) is an important Rosaceae family fruit crop, and its fruits contain many nutrients and phytochemicals that contribute to a healthy diet. Generally, apricots are appreciated by consumers for their unique flavor. In fact, flavor is not only a fruit quality factor that determines consumer preference, but also serves as a crucial clue to signal nutrient makeup to humans [14]. Fruit flavor is derived from a combination of taste and aroma $[15,16]$. The taste of apricot primarily depends on sugars and organic acids, whereas the aroma depends on a large number of volatile organic compounds (VOCs).

Sugars, organic acids, and volatiles of apricot were determined by HPLC, and sucrose and glucose were the major sugars in apricot fruit. Apricots cultivated in Syria since ancient times, and its area continues to expand, due to the fertility of its production and its valuable fruits which contain many nutrients that contribute to a healthy diet, as it is considered as one of the delicious taste fruits rich in sugars and vitamins, mineral salts, and others. Artificially dried apricots is distinguished by its sponge porous structure more than a sun-dried which is characterized by the dark orange color and illustrious bright surface, while artificially dried apricot has a light orange to yellow lemony color, as the sun dried product is characterized by the absence of the red color. The degree of hydration and moisture play an important role in the gloss and general appearance of the apricot, and when the moisture and humidity reach $30 \%$, it gives an improved and acceptable product.

The aim of the present study was to determine the sugar content in each of the fresh red grapes, raisins cultivars and fresh and dried apricot fruit, then to compare the concentration level of sugars in each of these four cultivars and identify the most higher content ratio of sugars in the studied cultivars.

The study also aimed to compare between the ratios of sugars in dry and fresh samples of the foresaid cultivars.

\section{Materials and Methods}

\subsection{Samples}

Both the imported fresh red grape samples available in the local markets, and the dry grapes, Yemeni black raisins were used in this study. Samples of fresh and dried apricots available in the markets were also used, in order to examine the sugar concentration in these four samples, and compare both cultivars of fresh and dry grapes and apricots in terms of sugar content, and to explain whether they were any significant differences in the ratio of sugar between both dry and fresh cultivars.

\subsection{Samples Preparation}

The samples were crushed using electric blender, and each type of samples was homogenized separately after removing the seeds from the samples before crushing. 


\subsection{Experimental}

a) Ratio of water was determined in each sample so as calculate the results of analysis in the form of a dry matter.

b) Analysis of sugars in the four samples used the standard methods AOAC-97720 C. Materials: all the chemicals used in the analysis are of high purity and the solid material from Sigma Corporation.

c) HPLC apparatus was used in determination of these sugars with the following specifications and operating conditions:

- Waters 1515 Isocratic HPLC Pump.

- Waters 2414 Refractive Index Detector.

- Column: EC 25014.6 Nucleodur 100-5 NH2-RP.

- Mobile Phase: $75.0 \%$ Acetonitrile in Distilled Water.

- Extraction Solution: 50.0\% Ethanol in Distilled Water.

Before the quantitative and qualitative determination of sugars in the samples we prepared a standard solution of a mixture contained five sugars: fructose, glucose, sucrose, maltose and lactose. With this standard solution of different sugars, and by injecting an amount of $10.0 \mathrm{~mL}$ for 20 minutes we defined the separation time for each of the different sugars, which were used to detect the presence of those sugars found in the samples under study, represented by different peaks in the chromatogram depending on the concentration of each component in the sample at a specific time.

Concentration of sugars was measured based on the peak area, using the Empower software for the two injections. The same manner was employed to monitor recovery for the process to determination of studied sugars. The chromatographic profile showed good separation to these sugars as shown in Table (1) and Figure (1) the calibration curve for a mixture of sugar, fructose, glucose, sucrose, maltose, and lactose.

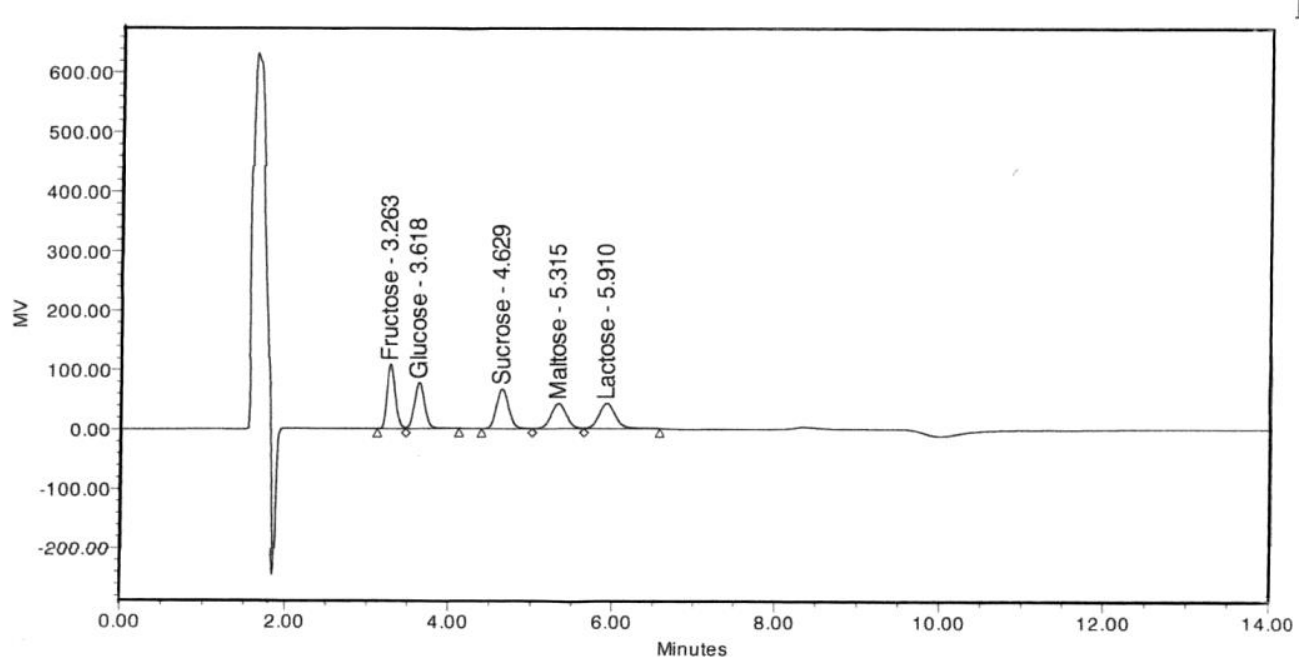

Figure 1: Sugars Chromatogram: fructose, glucose, sucrose, maltose and lactose in the standard solution using column -Ec 250/4.6 nucleodur 100-5NH2-RP \& refractive index detector. 
Table 1: Separation time, area and height of the chromatogram of sugars: fructose, glucose, sucrose, maltose and lactose in the standard solution

\begin{tabular}{lllllllll}
\hline No. & Peak name & $\begin{array}{l}\text { RT } \\
(\mathrm{min})\end{array}$ & $\begin{array}{l}\text { Area } \\
\left(\mu \mathrm{V}^{*} \mathrm{sec}\right)\end{array}$ & $\%$ Area & $\begin{array}{l}\text { Height } \\
(\mu \mathrm{V})\end{array}$ & $\begin{array}{l}\% \\
\text { Height }\end{array}$ & Amount & Units \\
\hline 1 & Fructose & 3.263 & 767245 & 23.61 & 107872 & 32.21 & 1.000 & $\%$ \\
2 & Glucose & 3.618 & 670377 & 20.62 & 76871 & 22.96 & 1.000 & $\%$ \\
3 & Sucrose & 4.629 & 679686 & 20.91 & 66268 & 19.79 & 1.000 & $\%$ \\
4 & Maltose & 5.315 & 540192 & 16.62 & 41908 & 12.52 & 1.000 & $\%$ \\
5 & Lactose & 5.910 & 592828 & 18.24 & 41937 & 12.52 & 1.000 & $\%$ \\
\hline
\end{tabular}

\section{Results and Discussion}

Sugars were determined by HPLC to extract the sugars found in both imported fresh red grapes, the dry grapes (raisins) and fresh and dried apricots using a separation column EC $250 \backslash 4.6$ Nucleodur 100-5 NH2 - RP and refractometer RID as a reagent. Fructose, glucose, sucrose, maltose sugars were detected in the four studied samples. The ratio of sucrose and maltose were low, while lactose was not present in this study. Table (2) shows the sugars recovery from the fresh grapes, and Figure (2) shows the chromatogram resulting from the extraction of fructose, glucose, sucrose and maltose in the fresh grapes, where fructose then glucose recorded a higher ratio of total sugars in the fresh grape, while sucrose and maltose were decreased in the sample and the average total ratio of sugars in the sample before drying accounted for $15.04 \%$, and $79.41 \%$ in the fresh grapes after drying.

Table (3) shows the sugars extracted from raisins, and Figure (3) shows the chromatogram resulting from the recovery of fructose, glucose, sucrose, maltose in raisins, where both glucose and fructose present at higher and convergent ratios in raisins, while the ratio of sucrose and maltose were decreased in the same sample, and the average of the total ratio of sugars in the raisins sample accounted for $67.75 \%$ before drying, and $79.65 \%$ after drying for the same sample.

Figure (4) and Table (4) show the chromatographic separation of sugars of the fresh apricots, where fructose, glucose, sucrose and maltose present in this sample before and after drying. Glucose, then sucrose recorded significant ratio of sugar in the sample of fresh apricots. The total percentage of four sugars accounted for $61.57 \%$ in this sample before drying, and $10.17 \%$ after drying.

When sugars were analyzed by HPLC to a sample of dried apricot which is used as a sheeted apricot (Kamaruddin) we obtained Figure (5) and Table (5), which show the chromatographic separation of sugars found in the dry apricot, as four sugars: fructose, glucose, sucrose and maltose were found in the sample of dry apricots before and after drying and removal of moisture. Moisture plays a significant role in this type of fruit, and that there were significant differences in the ratio of sugars, where glucose recorded higher ratio accounted for $30.15 \%$ of the sample, followed by fructose which dropped significantly, where the ratio of glucose accounted for $10.17 \%$ of the sample and then appeared sucrose with a lower ratio, followed by maltose which recorded a significant decline in the sample. The total percentage of sugar in dried 
apricots /sheeted apricots (Kamaruddin) accounted for $48.18 \%$ and after drying, the total sugars ratio recorded $65.94 \%$ of this sample.

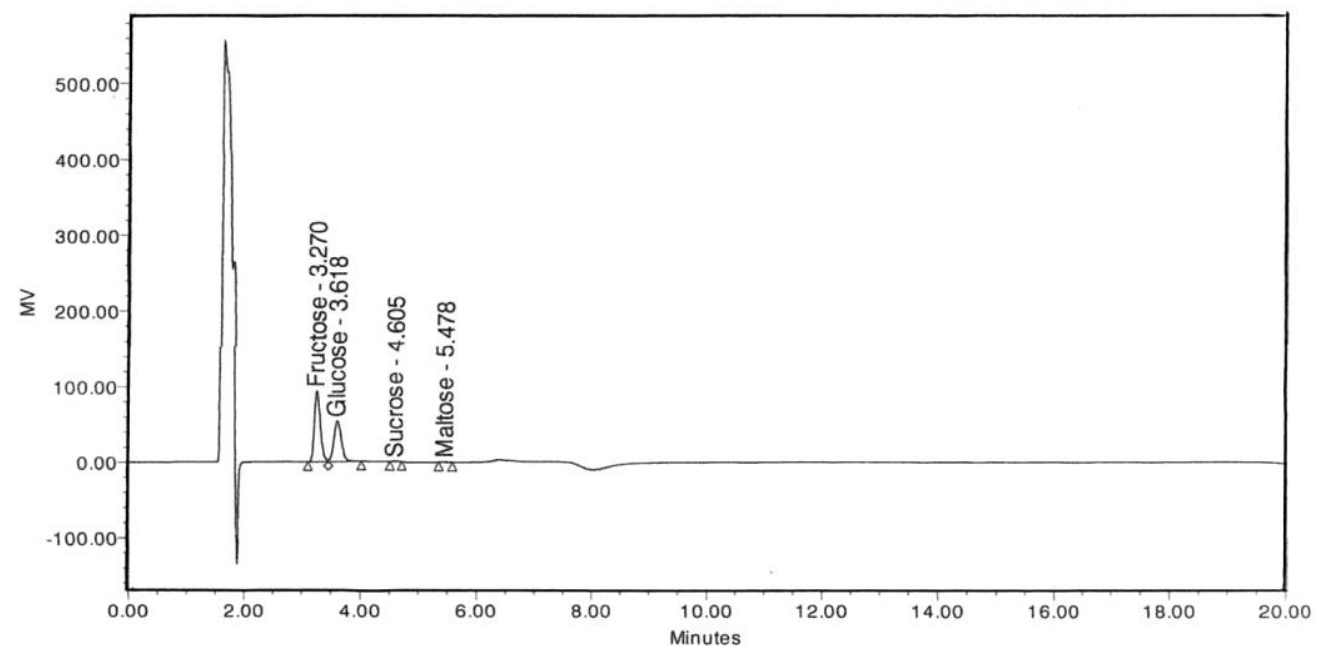

Figure 2: Chromatogram of: fructose, glucose, sucrose, maltose in the fresh grapes using column -Ec 250/4.6 nucleodur 100-5NH2-RP \& refractive index detector.

Table 2: Separation time, area and height of the chromatogram of sugars: fructose, glucose, sucrose and maltose in the fresh grapes.

\begin{tabular}{lllllllll}
\hline No. & Peak name & $\begin{array}{l}\mathrm{RT} \\
(\mathrm{min})\end{array}$ & $\begin{array}{l}\text { Area } \\
\left(\mu \mathrm{V}^{*} \mathrm{sec}\right)\end{array}$ & $\%$ Area & $\begin{array}{l}\text { Height } \\
(\mu \mathrm{V})\end{array}$ & $\begin{array}{l}\% \\
\text { Height }\end{array}$ & Amount & Units \\
\hline 1 & Fructose & 3.270 & 674500 & 58.52 & 93755 & 63.29 & 0.879 & $\%$ \\
2 & Glucose & 3.618 & 471383 & 40.90 & 53537 & 36.14 & 0.703 & $\%$ \\
3 & Sucrose & 4.605 & 3511 & 0.30 & 430 & 0.29 & 0.005 & $\%$ \\
4 & Maltose & 5.478 & 3271 & 0.28 & 402 & 0.27 & 0.006 & $\%$ \\
5 & Lactose & 5.910 & - & - & - & - & - & $\%$ \\
\hline
\end{tabular}

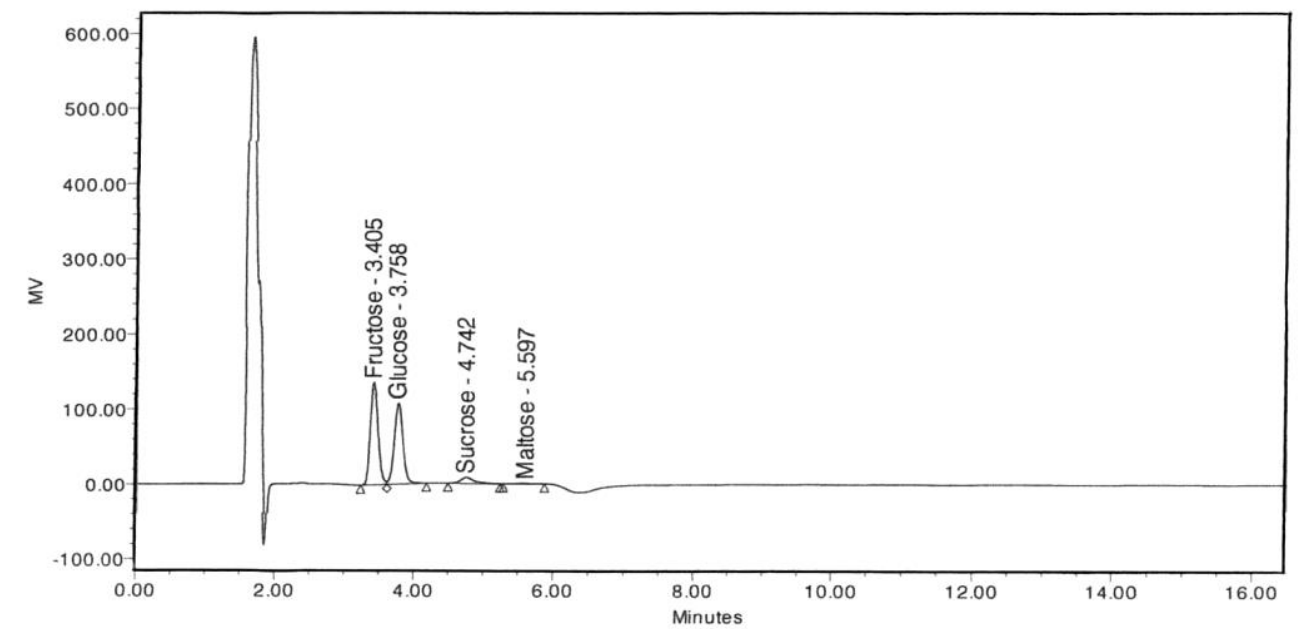

Figure 3: Chromatogram of: fructose, glucose, sucrose, maltose in raisins using column -Ec 250/4.6 nucleodur 100-5NH2-RP \& refractive index detector. 
Table 3: Separation time, area and height of the chromatogram of sugars: fructose, glucose, sucrose and maltose in raisins.

\begin{tabular}{lllllllll}
\hline No. & Peak name & $\begin{array}{l}\mathrm{RT} \\
(\mathrm{min})\end{array}$ & $\begin{array}{l}\text { Area } \\
\left(\mu \mathrm{V}^{*} \mathrm{sec}\right)\end{array}$ & $\%$ Area & $\begin{array}{l}\text { Height } \\
(\mu \mathrm{V})\end{array}$ & $\begin{array}{l}\% \\
\text { Height }\end{array}$ & Amount & Units \\
\hline 1 & Fructose & 3.405 & 1054079 & 50.22 & 136420 & 54.10 & 1.374 & $\%$ \\
2 & Glucose & 3.758 & 931464 & 44.38 & 107536 & 42.64 & 1.389 & $\%$ \\
3 & Sucrose & 4.742 & 103864 & 4.95 & 7656 & 3.04 & 0.153 & $\%$ \\
4 & Maltose & 5.597 & 9626 & 0.46 & 568 & 0.23 & 0.018 & $\%$ \\
5 & Lactose & 5.910 & - & - & - & - & - & $\%$ \\
\hline
\end{tabular}

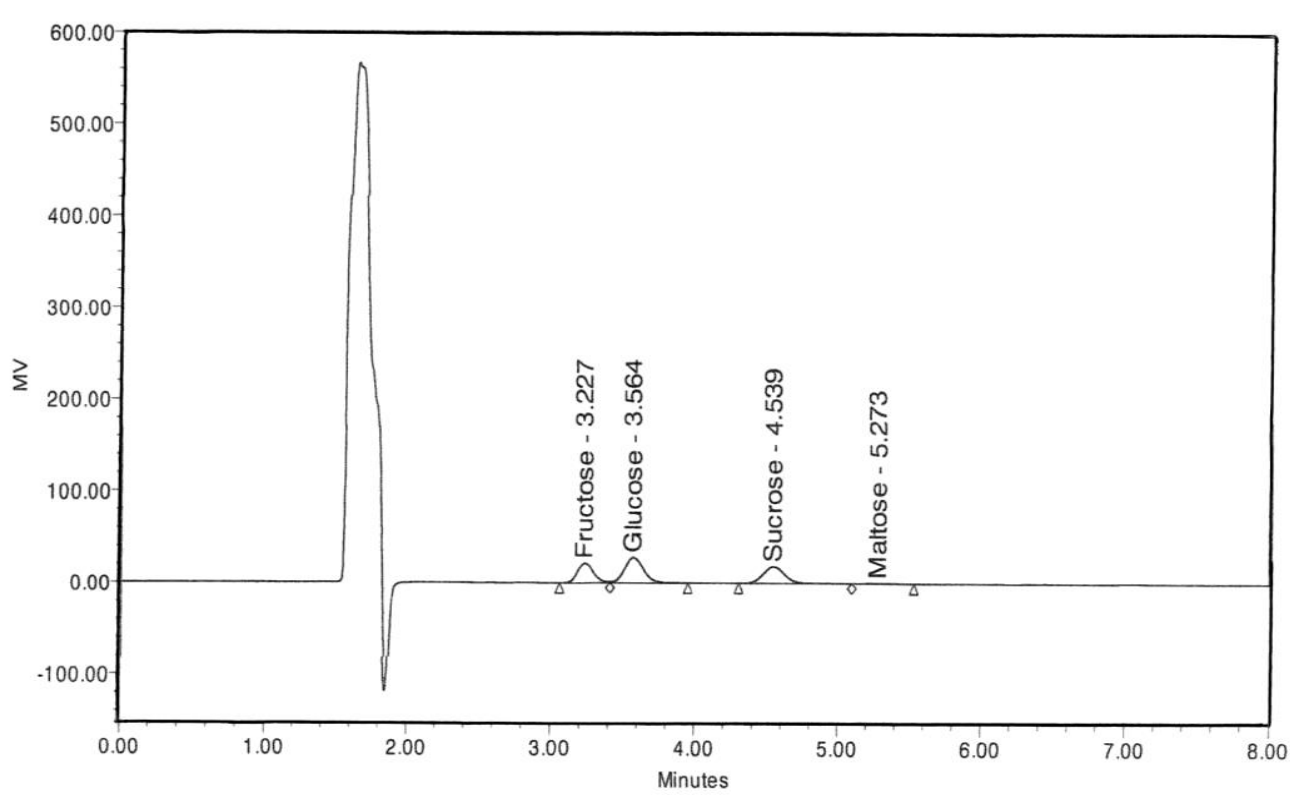

Figure 4: Chromatogram of: fructose, glucose, sucrose, maltose in fresh apricot using column Ec 250/4.6 nucleodur 100-5NH2-RP \& refractive index detector.

Table 4: Separation time, area and height of the chromatogram of sugars: fructose, glucose, sucrose and maltose in the fresh apricot.

\begin{tabular}{lllllllll}
\hline No. & Peak name & $\begin{array}{l}\mathrm{RT} \\
(\mathrm{min})\end{array}$ & $\begin{array}{l}\text { Area } \\
\left(\mu \mathrm{V}^{*} \mathrm{sec}\right)\end{array}$ & $\%$ Area & $\begin{array}{l}\text { Height } \\
(\mu \mathrm{V})\end{array}$ & $\begin{array}{l}\% \\
\text { Height }\end{array}$ & Amount & Units \\
\hline 1 & Fructose & 3.227 & 166941 & 26.65 & 21325 & 31.39 & 0.218 & $\%$ \\
2 & Glucose & 3.564 & 257169 & 41.05 & 27797 & 40.92 & 0.384 & $\%$ \\
3 & Sucrose & 4.539 & 193365 & 30.87 & 18125 & 26.68 & 0.284 & $\%$ \\
4 & Maltose & 5.273 & 8970 & 1.43 & 691 & 1.02 & 0.017 & $\%$ \\
5 & Lactose & 5.910 & - & - & - & - & - & $\%$ \\
\hline
\end{tabular}




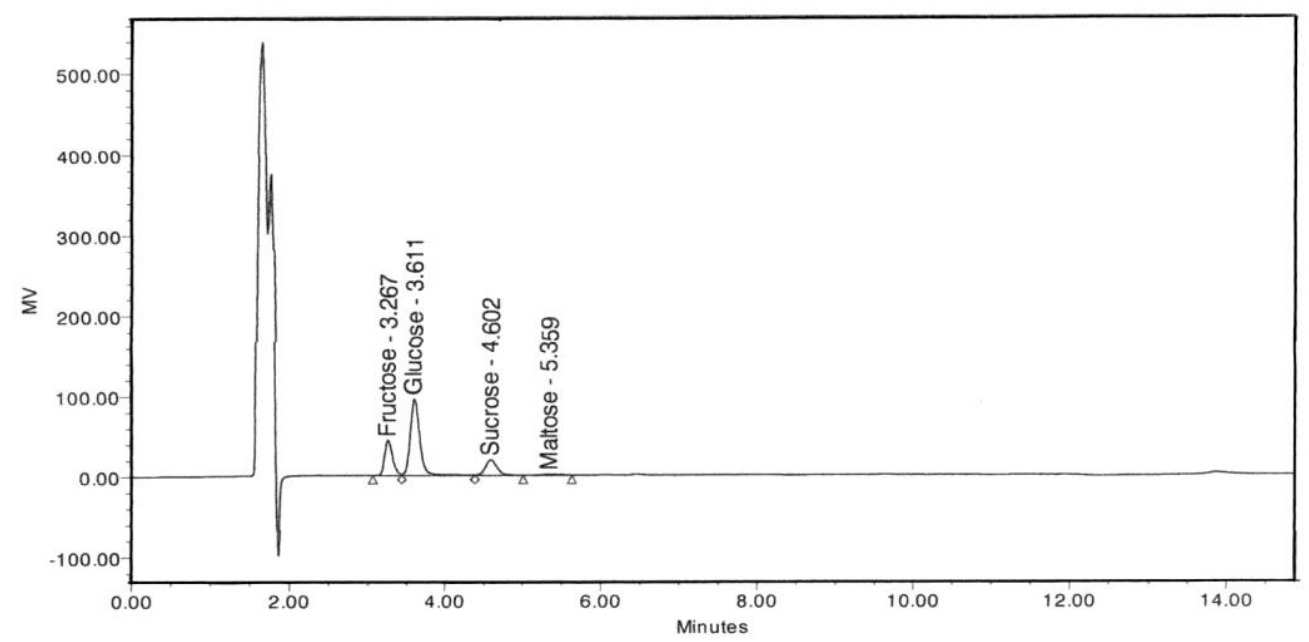

Figure 5: Chromatogram of: fructose, glucose, sucrose, maltose in dried apricot using column Ec 250/4.6 nucleodur 100-5NH2-RP \& refractive index detector.

Table 4: Separation time, area and height of the chromatogram of sugars: fructose, glucose, sucrose, maltose in the dried apricot.

\begin{tabular}{lllllllll}
\hline No. & Peak name & $\begin{array}{l}\text { RT } \\
(\mathrm{min})\end{array}$ & $\begin{array}{l}\text { Area } \\
\left(\mu \mathrm{V}^{*} \mathrm{sec}\right)\end{array}$ & $\%$ Area & $\begin{array}{l}\text { Height } \\
(\mu \mathrm{V})\end{array}$ & $\begin{array}{l}\% \\
\text { Height }\end{array}$ & Amount & Units \\
\hline 1 & Fructose & 3.267 & 314370 & 23.32 & 43668 & 27.44 & 0.410 & $\%$ \\
2 & Glucose & 3.611 & 823876 & 61.11 & 95139 & 59.78 & 1.229 & $\%$ \\
3 & Sucrose & 4.602 & 196904 & 14.61 & 19399 & 12.19 & 0.290 & $\%$ \\
4 & Maltose & 5.359 & 13010 & 0.97 & 945 & 0.59 & 0.024 & $\%$ \\
5 & Lactose & 5.910 & - & - & - & - & - & $\%$ \\
\hline
\end{tabular}

A comparison was conducted for the ratio of each sugar of examined sugars between both fresh grapes and imported dry grapes / raisins, and between imported fresh apricots and raisins and between imported fresh apricots and sheeted apricots (Kamaruddin), whether in the samples before drying, as represented by the Table (6) or in the samples after drying as represented by the Table (7), where the average results for each cultivar as well as the standard deviation (SD) and relative standard deviation (RSD) were calculated. The total sugars were also estimated before and after drying. The moisture content was also calculated due to their importance and impact on the results of samples analysis.

The ratio of sugars that have been identified and total sugars were found significantly higher in the four samples after drying compared to their ratio before drying, indicating statistically significant differences in sugars ratios present in the cultivar before and after drying. When the sugars contents in the fresh grapes and raisins were compared, it was found that the ratio of fructose in the raisins overweigh its ratio in fresh grapes by 4 -fold, where the fructose ratio accounted for $31.71 \%$ in raisins compared to $8.24 \%$ in fresh grapes. Glucose content increased in raisins by 5 -fold its ratio in fresh grapes, as it recorded $32.23 \%$ and $6.71 \%$ respectively. There was an increase in sucrose content of raisins compared to the fresh grapes, while a decrease was found in maltose content of raisins compared to the fresh grapes, and the ratio of total sugars of fructose, glucose, sucrose and maltose in raisins recorded $67.75 \%$ before drying the raisins 
sample, but after drying, the total sugars ratio in the sample increased to $79.65 \%$, while the ratio of total sugars in fresh grapes before drying was $15.04 \%$ and after drying it increased to $79.41 \%$. The ratio of total sugars in the fresh grapes and raisins after drying was almost equal, which explained to us in this study, the importance of drying and concentration of different kinds of sugars in the investigated cultivars, where the high percentages of fructose, glucose, sucrose and maltose and total sugars were found more in raisin than in the fresh grapes.

When comparing the ratio of sugars: fructose, glucose, sucrose and maltose between both the fresh and dry apricot fruit, it became obvious that there were statistically significant differences between each type of sugars and between the total sugars found in these two cultivars. We found that the percentage of fructose in the dry apricots increased four times in the fresh apricots fruit as the ratio stood at $10.17 \%$ while its content in the fresh sample accounted for $2.45 \%$. Significant increase of glucose ratio was observed in both cultivars, as its ratio in the fresh apricot fruit accounted for $4.27 \%$, and the content increased seven times its ratio in the fresh fruit as it recorded $30.15 \%$ in the dried apricots. The ratio of sucrose and maltose in the dried apricots has doubled compared to their ratio in the fresh apricots fruit. When comparing the total percentage of sugars in both fresh and dried cultivars, the ratio of total sugars increased almost five times the ratio in the dried cultivar, i.e. from $10.17 \%$ in the fresh apricots fruit to $48.18 \%$ in the dried apricots. When the drying process was performed on each of the fresh and dried apricots/sheeted apricot (Kamaruddin), the ratio of total sugars in the fresh apricots fruit after drying increased to $61.57 \%$, while it increased more in the sheeted apricots (Kamaruddin) after drying and reached $65.94 \%$, as shown in Table (6), which shows the mean ratios of fructose, glucose, sucrose and maltose and the average ratio of total sugars, SD, RSD, and relative humidity in each of the fresh grapes, raisins, fresh and dried apricots.

\section{Conclusion}

In this study it became obvious that there was a difference in the sugar content for fructose, glucose, sucrose and maltose in each of the fresh grapes and (raisins), and in the fresh and dried apricots fruits, where the fructose and glucose present as major sugars that contribute to the sweet taste of the fruit. The study also showed that the ratio of fructose, glucose, sucrose and maltose (total sugar) was higher in the dry grapes (raisins), compared to its presence in the fresh grapes, and also the dried apricots contains high levels of the four sugars (total sugar) compared to its presence in the fresh apricots fruit.

\section{Acknowledgment}

The author would like to thank Department of Chemistry, Faculty of Science, Princess Nora bint Abdul Raman University for their cooperation.

\section{References}

[1] Jacqueline Barrett and Peter Glbson, "Clinical Ramification of Mal absorption of Fructose and Other Short-chain Carbohydrates." Practical Gastroenterology. 53, 51 (2007) (Aug).

[2] Fateh Aljane, Ines Toumi and Ali Ferchichi, "HPLC determination of sugars and atomic absorption analysis of mineral salts in fresh figs of Tunisian cultivars" African Journal of Biotechnology, 6(5), 599-602 (2007). 
[3] Takako Masuda, Kei-ichi Kitahara, Yoshihiro Aikawa and Sadoa Arai, "DETERMINATION OF CARBOHYDRATES BY HPLC-ECD WITH A NOVEL STATIONARY PHASE PREPARED FROM POLYSTYRENE-BASED RESIN AND TERIARY AMINES". Analytical Sciences, 17, 895 (2001).

[4] Enzo Moro, Roberto Majocchi, Cinzia Ballabio, Silvia Molfino, Patrizia Restani, "A Rapid and Simple Method for Simultaneous Determination of Glycerol, Fructose, and Glucose in Wine" American Journal of Enology and Viticulture, 58(2), 279-282 (2007).

[5] The Oxford English Dictionary entry at "currant" "raisins of curauntz n. (also called raisins of Corinth).

[6] Dom Costello "kew garden explanation".kew.org.Jan.2013.

[7] Antonia Chiou, Eirini Panagopoulou, Fotini Gatzali, Stephania De Marchi and Vaios Karathanos, "Anthocyanins content and antioxidant capacity OF Corinthian currants" (Vitisvinifera L, var. Apyrena) Food Chemistry. 146, 157 (2014).

[8] Li, Lingling; Wang, Zhengfu; Hu, Xiaosong, Jihong Wu, Xiaojun Liao, Fang Chen and Guanghua Zhao, "Drying Effects of Two Air-Drying Shelters in a Pilot Test on Sultana Grapes." Journal of Food Processing Engineering, 33, 162 (2010). http://dx.doi.org/10.1111/j.17454530.2008.00266.x

[9] Zhao Chen, Chuanhe Zhu and Ziqiang Han, "Effects of Aqueous Chlorine Dioxide Treatment on Nutritional Components and Shelf-Life of Mulberry Fruit (Morusalba L.)." Journal of Bioscience and Bioengineering, 111(6), 675-681 (2011).

[10] A.A. Gowen, N. Abu-Ghannam, J.M. Frias, J.M. Barat, A. Andres and J.C. Oliveira, "Comparative Study of Quality Changes Occurring on Dehydration and Rehydration of Cooked Chickpeas (Cicerarietinum L.) Subjected to Combined Microwave-Convective and Convective Hot Air Dehydration." Journal of Food Science, 71, 282 (2006). http://dx.doi.org/10.1111/j.17503841.2006.00082.x

[11] Saliha Erenturk, Sahin Gulaboglu, Selahattin Gultekin, "The Effects of Cutting and Drying Medium on the Vitamin C Content of Rose Hip during Drying." Journal of Food Engineering, 68(4), 513 (2005). http://dx.doi.org/10.1016/j.jfoodeng.2004.07.012

[12] Paola Russo, Giuseppina Adiletta, Marisa Di Matteo, "The Influence of Drying Air Temperature on the Physical Properties of Dried and Rehydrated Eggplant." Food and Bioproducts Processing, 91, 249-256 (2013). http://dx.doi.org/10.1016/j.fbp.2012.10.005

[13] Feryal Karadeniz, Robert Durst, and Ronald Wrolstad, "Polyphenolic composition of raisins", Journal of Agricultural and Food Chemistry, 48(11), 5343-5350 (2000).

[14] Stephen Goff and Harry Klee. "Plant volatile compounds: Sensory cues for health and nutritional value?" Science, 311 (5762), 815-819 (2006). doi: 10.1126/science.1112614. [PubMed] [Cross Ref]

[15] Adel Kader, "Flavor quality of fruits and vegetables." Journal of the Science of Food and Agriculture, 88, 1863-1868 (2008). doi: 10.1002/jsfa.3293. [Cross Ref]

[16] Harry Klee, Improving the flavor of fresh fruits, Genomics, biochemistry, and biotechnology. New Phytol., 187, 44 (2010). doi: 10.1111/j.1469-8137.2010.03281.x. [PubMed] [Cross Ref]

*Corresponding author.

E-mail address: maalnoussier@ pnu.edu.sa 